\title{
Research of Deformation Law by Speed in Temperature Field of Carding Machine Cylinder
}

\author{
Wang Yongyan ${ }^{1, a}$, Yang Lei ${ }^{1, b}$ and Zeng Chunlei ${ }^{1, c}$ \\ ${ }^{1}$ College of Electromechanical Engineering, Qingdao University of Science and Technology, \\ Qingdao 266061, China \\ awangyongyan@163.com, b1445661884@qq.com, czcl82216@126.com
}

Keywords: carding machine, cylinder, heat-structure coupling, Optimal design.

\begin{abstract}
The relationship between rotation velocity and displacements of cylinder is researched. Based on the heat-structure coupling method of AWE software, the cylinder is simulated. The original temperature field under certain velocities is obtained, and the correction depends on experiments is made. In accordance with the improved temperature field, the cylinder deformation model is count out by heat-structure coupling method. The modification of velocities of cylinder could be realized through the variation of the power of carding. And the deformation of cylinder is obtained. Then information could be analyzed to find the math expression and curves for the relation between rotation velocities and deformations.
\end{abstract}

\section{Introduction}

In order to improve the production and quality of cotton textiles, carding machine has entered the high-yield stage. Many textile enterprises by increasing the rotating speed of cylinder and the carding area to improve production. Now many international advanced cylinder's speed of high production carding machine can reach $1000 \mathrm{r} / \mathrm{min}$, domestic carding machines are trying to improve the cylinder speed But homemade carding machine is temporarily unable to keep safe and stable operation at higher speeds. Besides, the existing experimental conditions in textile mill are quite hard to get critical data about cylinder, such as deformation of the cylinder. And the deformation of the cylinder would immediately affect the smoothness of the surface on cylinder and the gauge between the cylinder and the cover, thus affecting the efficiency of carding. To solve this problem, this report proposes a method to simulated heat-structure coupling field, by changing the temperature field to deduce the deformation of the cylinder at high speed. Consequently, the working conditions of the existing carding machine could be analyzed after improving the rotating speed of cylinder, which provides a theoretical basis and reference for improving the rotating speed of cylinder. This report uses software to simulate the temperature and deformation model of the cylinder. At the same time, field trials are conducted to ensure that the simulation model is consistent with the actual cylinder temperature field and deformation field, thus ensuring the reliability of simulation results. On the basis, the relationship between rotating speed and the amount of deformation of cylinder has been taken for further analysis and research.

\section{The heat-structure coupling analysis of cylinder}

Preliminary calculations of cylinder's temperature field model. In the first place, a carding machine cylinder of $3 \mathrm{~d}$ model is set up in the Pro/E software. The material selection is gray cast iron (HT200). Through the relevant interface of Pro/E and ANSYS, the model is imported into ANSYS Workbench. To simplify the calculations, finite element modeling does not involve the cylinder shaft, bearings, cover, apron, etc. And some of the fine structures of all bolts, screw, balance iron are also ignored. Cylinder dimensional geometric model is shown inFigure 1. 


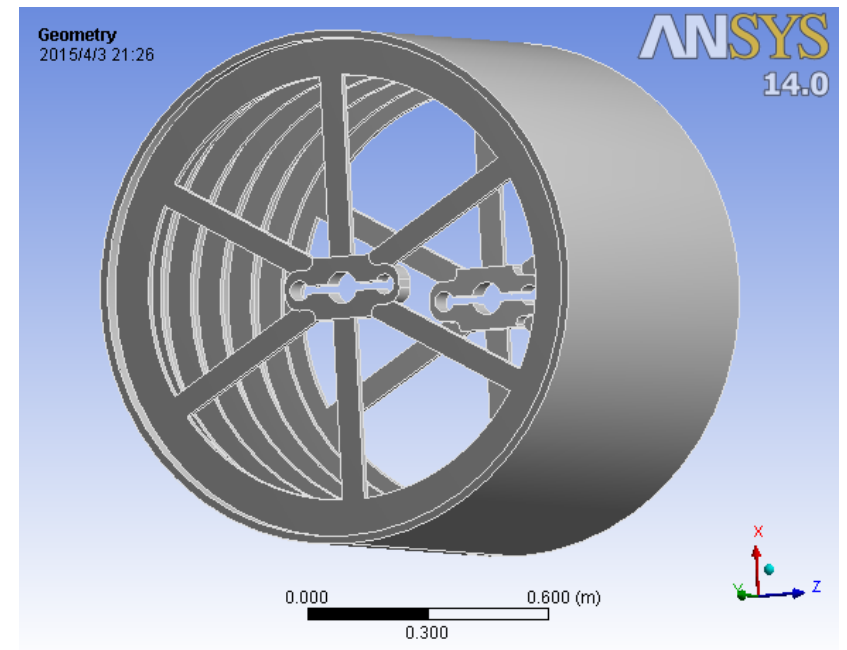

Fig. 1 The three-dimensional model of the cylinder of carding machine

After meshed by hexahedral elements, the model generates 31,254 units, 67,896 nodes. Temperature field model of cylinder has been initially simulated at a rotating speed of $478 \mathrm{r} / \mathrm{min}$. Through the analysis of heating and cooling of the cylinder, and on-site temperature measurement, cylinder heat source and heat dissipation of the related data are obtained. Then, temperature load and thermal convection coefficient has been applied on cylinder. Then the preliminary temperature field model of cylinder is calculated out as shown in the figure 2 below.

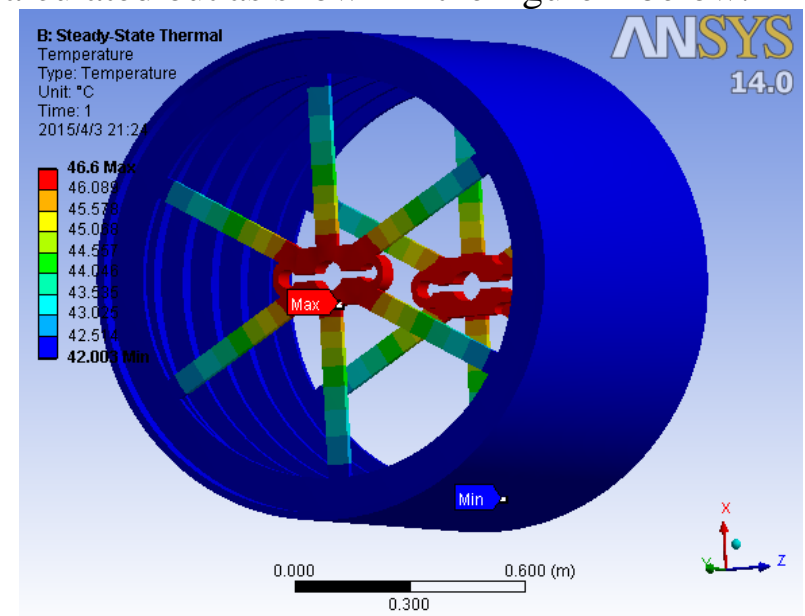

Fig.2 Unmodified temperature field model of cylinder

Figure 2 shows that highest temperature points in the cylinder are located on the contact position of the panel and the cylinder. The reason is that this area is in close contact with the heat source and accepting direct heat conduction of the heat source. In general, the temperature field model calculated by analysis software has some deviations with the actual temperature, which is a normal phenomenon. So, feedback of test data is needed to correct the analysis method. Through repeatedly test corrections until the simulation data and experimental data maintained in a smaller deviation, the thermal analysis can be proved to be accurate and reliable.

Test correction and results comparing. First, the carding machine operates steadily for $120 \mathrm{~min}$ while the rotating speed of cylinder is $478 \mathrm{r} / \mathrm{min}$. And until its balance, rotating speed at this time is recorded by tachometer. Then, temperature at the edge of cylinder body panel is recorded by the infrared thermometer, while takes the mean value of ten times. The contrast of the measured temperature and the unmodified model is shown in Table 1. 
Tab.1 The contrast of the measured temperature and the unmodified model

Model Test Deviation

temperature $\left({ }^{\circ} \mathrm{C}\right) \quad$ temperature $\left({ }^{\circ} \mathrm{C}\right)$

$42.041 \quad 44.6 \quad 5.7 \%$

The deviation of data is large by comparing measurements of infrared thermometers and temperature field model. So, improving the model is necessary. Since cylinder is extremely complex, for the need of simulation, the structure is simplified. Thereby, the integrity of the actual cylinder's heat-transfer- system simulation is not high. While larger cylinder, air status of each site is different, so the heat transfer coefficient of system is difficult to accurately infer from theory. So, this paper will compare the data from initial simulation of temperature field and tests. By changing the thermal convection coefficient to change the temperature field model, and ultimately makes the temperature of the temperature field model with experimental measurements basically reached agreement. Thereby, it further increases the accuracy of Hot - structural deformation simulation. After several rounds of verification contrast, all the heat convection coefficient changed to 0.008 times of the original, so that the temperature field simulation model and experimental measurements of the temperature consistent basically. Contrast of temperature field model with re-change thermal convection coefficient and the measured temperature is shown in Table 2.

Tab. 2 The contrast of improved model and the measured temperature

\begin{tabular}{ccc}
\hline $\begin{array}{c}\text { Model } \\
\text { temperature }\left({ }^{\circ} \mathrm{C}\right)\end{array}$ & $\begin{array}{c}\text { Test } \\
\text { temperature }\left({ }^{\circ} \mathrm{C}\right)\end{array}$ & Deviation \\
\hline 44.203 & 44.6 & $0.9 \%$
\end{tabular}

After the comparison, it can be found that the temperature deviation of cylinder model has been significantly lower than previous, indicating improved thermal analysis method is feasible and could be carried out on the basis of heat - structure coupling analysis, thus the results can also be considered to be authentic.

Thermal-structural coupling analysis. In ANSYS Workbench, sequential coupling method could be utilized to do thermal-structure coupling analysis of cylinder components. As a kind of load, the analyzed temperature field model can be added into the structural analysis; apply surface pressure load, the angular velocity of load and the displacement constraints, then the equivalent deformation model of cylinder(shown as figure 3) could be obtained after calculation.

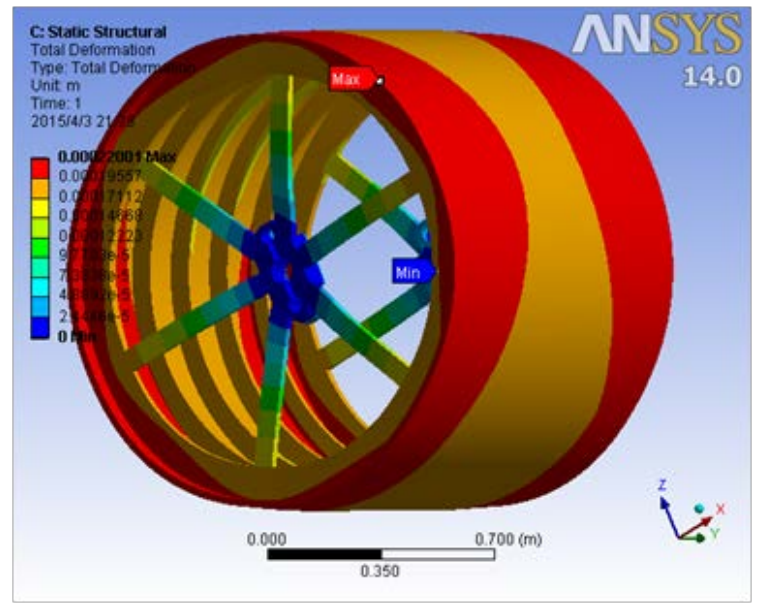

Fig.3 The deformation model of cylinder

There is a high demand for carding machine to keep the stability of the gauge between cylinder and cover plate. It is obviously to see from the result of thermal-structure coupling analysis, the maximum distortion could be found at the edge of roller's barrel; and it expands outward along the cylinder radial, when the cylinder's rotational speed is $478 \mathrm{r} / \mathrm{min}$, its maximum deflection will reach 
to $0.21951 \mathrm{~mm}$. In addition, the position that cylinder has maximum deformation will have direct influence to the gauge between cylinder and cover plate, therefore, it should be controlled strictly.

In the cotton textile factory, when the carding machine is in the regular work, the acceptable maximum deflection of cylinder is $\Delta=0.2 \sim 0.3 \mathrm{~mm}$. Within the scope of regular production, it reaches the quality standard of cotton carding and composites requirement of factory. However, if the rotating speed is increased, whether the gauge between cylinder and roller could be satisfied should be investigated deeper further.

\section{The study of the relationship between Cylinder rotation speed- deformation}

Data of thermal-structural coupling analysis. Adjust the power setting of carding machine to make the cylinder of carding machine get temperature balance at different rotating speed, then record current temperature. The data of deformation (as shown in table 3) could be obtained after doing the cylinder heat - structure coupling analysis respectively in ANSYS Workbench.

Tab.3 Data of rotating speed and deformation

\begin{tabular}{ccc}
\hline Speed(r/min) & Speed(rad/s) & Deformation $(\mathrm{mm})$ \\
\hline 119 & 12.46 & 0.18979 \\
154 & 16.13 & 0.19096 \\
214 & 22.41 & 0.19319 \\
257 & 26.91 & 0.19575 \\
317 & 33.20 & 0.19960 \\
385 & 40.32 & 0.20603 \\
426 & 44.61 & 0.21081 \\
478 & 50.06 & 0.21951
\end{tabular}

It could be found from table 3 that with the increase of rotating speed, the cylinder's maximum deformation increases. Hence, it is very significant to investigate the relationship between the rotating speed and deformation.

Origin data fitting. The data in table 3 is inputted to Origin software for data fitting and set to generate a quadratic curve. The curve of relationship between cylinder's deformation and rotating speed could be revealed in the graph 4.

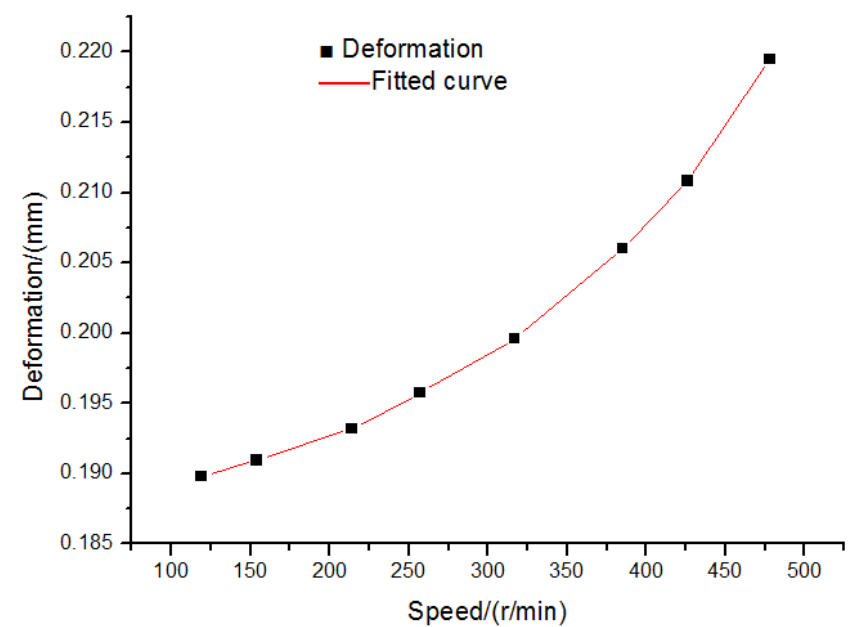

Fig.4 The Origin curve of deformation and rotating speed

Meanwhile, the mathematical expression of the curve deprived from Origin software is shown below.

$$
\mathrm{y}=0.19199+(-3.8165) \times 10^{-5} \mathrm{x}+1.97152 \times 10^{-7} \mathrm{x}^{2}
$$


AWE analyzes the relationship between speed and the amount of deformation. The optimized design model of AWE software has the function that through changing single parameter variable to affect the output result. In this report, the optimized design model of AWE software will be applied to analyze the relation between rotating speed and deformation of the cylinder.

In this report, the optimization design environment is set according to the above heat - structure coupling analysis results. Choose cylinder's rotating speed as "Input", the maximum deformation of cylinder roller as “Output”, and set the rotating speed's bond between 1 1000 r/min (equal to $1 \sim 105 \mathrm{rad} / \mathrm{s}$ as the unit in AWE). Update the data of optimized design data and do the calculation. The analyzed data of these two parameters' relationship curve could be shown in Figure 5.

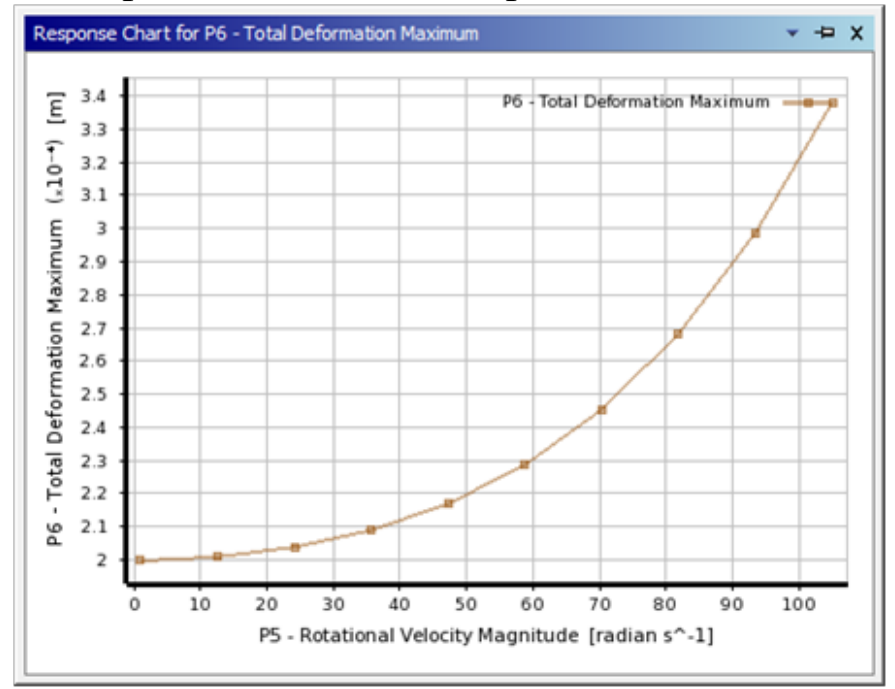

Fig.5 The Origin curve of deformation and rotating speed

Comparison and validation. After observing and comparing Figure4 and 5, it could be found that the two curves (one is from origin and the other is from AWE optimized design model) have excellent similarity. This could illustrate that the curve of relationship between cylinder's rotating speed and deformation deprived by heat-structure analysis is reliable. Meanwhile, in theory, the mathematical expression of cylinder's rotating speed- deformation from Origin software is correct.

Then, the mathematical expression of cylinder's rotating speed- deformation is verified below. Utilize the mathematical expression(1), it could be calculated that when the rotating speed is 1000 $\mathrm{r} / \mathrm{min}$, the deformation is $0.350997 \mathrm{~mm}$. When use ANSYS Workbench to simulate the carding machine at the rotating speed of $1000 \mathrm{r} / \mathrm{min}$, we could get the deformation is $0.34661 \mathrm{~mm}$. This result is very close to the previous one and the deviation is only 1.24. Therefore, it could be concluded that the mathematical expression(1) is correct.

\section{Summary}

This report uses the thermal-structural coupling analysis model of ANSYS Workbench software to analyze cylinder of carding machine under different rotating speed and get its deformation. On the basis of analysis, the curve and mathematical expression of cylinder's rotating speed and deformation could be concluded. Through analyzing these two stuffs, some conclusions can be obtained.

The deformation of cylinder can increase with the increase of rotating speed. It indicates that if the rotating speed is increased significantly, the deformation will change heavily, which will also have adverse effect of the gauge between cylinder and cover plate. To keep cylinder under regular work, there should be some methods like changing the structure to decrease the cylinder's deformation. 
The rate of change of the curve is in direct proportion to rotating speed of cylinder. It shows that when the rotating speed is higher, the deformation's increment is bigger. Therefore, when the rotating speed of cylinder increases to some extent, it will be harder to increase to another degree. Hence, to increase the carding efficiency, some factors like increasing carding area should be considered.

\section{Acknowledgement}

Special thanks to mechanics research center, Qingdao university of science and technology to provide me all the conditions and facilities for this experiment. Gratefully acknowledge the financial support from the National Natural Science Fund project (51374134), the Chinese Education Ministry doctoral program project (20133719110005), and the Qingdao basic research project of science and technology program(12-1-4-3-(12)-jch).

\section{Reference}

[1] WANG Yongyan, WU Yang: Optimizing analyses of rotation flat key dimension parameter in carding machine . Cotton Textile Technology.43(2015), p. 33-36 .

[2] SUN Pengzi: Discussion of cylinder speed of carding machine. Cotton Textile Technology. 4(2001),p. 32-35.

[3] WANG Kai: High-speed \& precision textile machinery bearing study . Zhejiang, Zhejiang University(2013)

[4] WANG Juan: Theoretical research \& flow field analysis for key components of carding machine. Qingdao, Qingdao University of Science and Technology(2013)

[5] FEI Qing: Characteristics and development of domestic and foreign production card analysis (on). Modern Textile Technology. 3(2009), p. 58-62 .

[6] FEI Qing: Characteristics and development of domestic and foreign production card analysis (below). Modern Textile Technology. 4(2009), p. 45-50.

[7] ZHANG Bo: Direct-drive spindle lathes thermal characteristics analysis and optimization. Chongqing, Chongqing University(2010)

[8] Pu Guangyi: ANSYS Workbench based tutorial and example explanation (Second Edition). Beijing,China Water Power Press(2013) 